Article

\title{
Fe Oxides Loaded on Carbon Cloth by Hydrothermal Process as an Effective and Reusable Heterogenous Fenton Catalyst
}

\author{
Honghui Yang *, Bofang Shi and Silan Wang \\ Department of Environmental Science and Engineering, Xi'an Jiaotong University, Xi'an 710049, China; \\ shi1003324005@stu.xjtu.edu.cn (B.S.); wsl3116019006@stu.xjtu.edu.cn (S.W.) \\ * Correspondence: yanghonghui@mail.xjtu.edu.cn
}

Received: 27 April 2018; Accepted: 10 May 2018; Published: 15 May 2018

\begin{abstract}
Iron based heterogeneous Fenton catalysts are attracting much attention for its economic and environmental friendly characteristics. In this study, iron oxides loaded carbon cloth (assigned as Fe@CC) was prepared using hydrothermal hydrolysis of $\mathrm{Fe}\left(\mathrm{NO}_{3}\right)_{3}$. The specific surface area of Fe@CC determined by $\mathrm{N}_{2}$ adsorption-desorption Brunauer-Emmett-Teller method was up to $1325.5 \mathrm{~m}^{2} / \mathrm{g}$, which increased by $81.8 \%$ compared with that of native carbon cloth mainly due to the loading of iron oxide. XPS (X-ray photoelectron spectroscopy) spectra confirmed that the iron oxide on the carbon surface included mainly FeOOH. Its heterogeneous Fenton-like activity was determined using Acid Red G as a model substrate for degradation. Fe@CC maintained high and relatively stable activity during 11 tests, and it showed high COD (Chemical Oxygen Demand) removal efficiency and high apparent $\mathrm{H}_{2} \mathrm{O}_{2}$ utilization efficiency. The homogeneous Fenton reaction using the amount of leached Fe(III) suggested that the surficial reaction on Fe@CC was dominant. The stability and the mechanism for gradual decrease of activity during the first 4 tests were also discussed.
\end{abstract}

Keywords: heterogeneous Fenton reaction; iron oxide; $\mathrm{FeOOH}$; carbon cloth; hydrothermal hydrolysis

\section{Introduction}

Fenton reaction is one of the extensively studied advanced oxidation process that is effective for pollutants treatment [1-5]. This process shows obvious advantages on oxidizing recalcitrant substances, and it is usually used as pretreatment process to increase the biodegradability of the wastewater by increasing the $\mathrm{B} / \mathrm{C}$ value [6-8]. However, it also shows some inevitable drawbacks mainly in formation of ferric hydroxide sludge above $\mathrm{pH} 4.0$ [9], and difficulty in catalyst recovery from the sludge. Therefore, the heterogeneous Fenton-like process, in which the production of ferric hydroxide sludge could be avoided and the recovery of the catalysts could be easily implemented by separation, is attracting much attention.

However, the heterogeneous Fenton-like process also shows clear shortage of lower reaction rate comparing with the homogeneous Fenton process. Therefore, one of the main topics of these studies focused on increasing the reaction rate by optimizing the components, morphology, supports, preparation methods and reaction parameters. Among the rapid growth of literatures reported, iron-based heterogeneous Fenton-like catalysts, which is mainly composed of environmental friendly element and low cost, are intensively studied [10-12].

For the heterogeneous catalysts, a significant issue that could affect its activity was the surficial concentration of its active components. Therefore, the catalysts were usually prepared in high surface area morphology or loaded on the materials with high surface area to form a highly dispersed status to enhance the contacting opportunity among the catalysts and reactants [13]. The treatment 
efficiency on textile wastewater using $\mathrm{Fe}_{2} \mathrm{O}_{3} /$ carbon as the catalyst for heterogeneous Fenton reaction was studied [14]. The results showed that the composites with high $\mathrm{Fe}_{2} \mathrm{O}_{3}$ content were effective to adsorb contaminants in textile wastewater, and the adsorptive capacity increased with the surficial iron concentration. While the dosage of catalyst used in this study was as high as 100-300 g/L for the low surface area of around $4.9 \mathrm{~m}^{2} / \mathrm{g}$. The high catalyst dosage limits its industrial utilization. It is well accepted that the supports highly affect the catalytic activity of the active components [15-17]. The $\alpha-\mathrm{Fe}_{2} \mathrm{O}_{3} @$ porous hollow carbonaceous microspheres $\left(\alpha-\mathrm{Fe}_{2} \mathrm{O}_{3} @ \mathrm{PHCMs}\right.$ (Porous Hollow Carbonaceous Microspheres)) prepared by calcination and hydrothermal reaction showed high Fenton-like catalytic activity and absorption capacity of $539.8 \mathrm{mg} / \mathrm{g}$. The adsorption capacity could be regenerated with Fenton-like reaction efficiently [18]. However, the size of PHCMs was around 1-2 $\mu \mathrm{m}$, which is hard to be separated. The active carbon in Fe/active carbon showed positive effects on the Fenton-like reaction by offering high adsorption capacity [19]. The localization of Fe fine particles in the micropores of the active carbon could facilitate the oxidation process and therefore improved the TOC removal rate. However, the stability of the catalysts on heterogeneous Fenton reaction was not evaluated. Three commercial active carbon materials were used as supports of iron oxides for preparing Fenton-like catalysts [20]. The Norit commercial active carbon was found to be the best support for its high surface area and large micropores that favors the adsorption of molecules and the Fe dispersion. However, the high dispersion in this catalyst also facilitates the iron leaching, and the stability of the catalysts was not studied. $\mathrm{Fe}_{2} \mathrm{O}_{3}$ loaded active carbon fiber catalyst $\left(\mathrm{Fe}_{2} \mathrm{O}_{3} / \mathrm{ACF}\right)$ was prepared for Fenton reaction by calcining the impregnated active carbon fiber with $\mathrm{Fe}\left(\mathrm{NO}_{3}\right)_{3}$ at $500{ }^{\circ} \mathrm{C}$ [21], and the result indicated that $\mathrm{Fe}_{2} \mathrm{O}_{3} / \mathrm{ACF}$ showed relatively low activity on Fenton reaction. This result could be attributed to the improper selection of ACF support.

According to the above literatures, iron oxides-based catalysts are potential candidates for heterogeneous Fenton reaction. Among these catalysts, a support that could highly disperse the iron oxides particles on its surface and be easy to separate should be its important features. Most of these reported active components reported were loaded on powders that are still difficult to be separated. Furthermore, most of the studies used impregnating method followed with calcination, in other words, the separability or stability of the reported results need to be improved further. In this study, carbon cloth (CC), which possesses high specific surface area, higher chemical stability and easy to be separated and regenerated once deactivated, were used as a support to prepare high active iron oxides (mainly FeOOH) loaded catalysts to improve the exposure of surficial active sites for heterogeneous Fenton reaction. The results suggested that the prepared Fe@CC showed higher specific surface area by $81.8 \%$ compared with that of carbon cloth, which suggested that $\mathrm{FeOOH}$ was dispersed/covered on the surface with high specific surface area. The effects of experimental parameters, including hydrothermal temperature for catalyst preparation, $\mathrm{pH}$ value, $\mathrm{H}_{2} \mathrm{O}_{2}$ dosage, and the stability of the catalytic activity were studies. The Fenton-like reaction results showed that this catalyst was highly active and stable.

\section{Results and Discussion}

\subsection{Characterization of Catalysts}

During hydrothermal reaction, $\mathrm{Fe}\left(\mathrm{NO}_{3}\right)_{3}$ could be hydrolyzed according to the Equation (5). $\mathrm{HNO}_{3}$ could be decomposed as shown in Equation (1), and $\mathrm{Fe}(\mathrm{OH})_{3}$ stacked on the surface of carbon cloth could also be dehydrated to form $\mathrm{FeOOH}$ and $\mathrm{Fe}_{2} \mathrm{O}_{3}$ according to Equations (2) and (3). Therefore, the hydrolysis process shown in Equation (5) could be promoted. The consequence of these reactions might lead to the formation of Fe@CC catalysts.

$$
\begin{gathered}
\mathrm{Fe}\left(\mathrm{NO}_{3}\right)_{3}+3 \mathrm{H}_{2} \mathrm{O} \rightarrow \mathrm{Fe}(\mathrm{OH})_{3}+3 \mathrm{HNO}_{3} \\
\mathrm{HNO}_{3}+\mathrm{C} \rightarrow \mathrm{NO}_{\mathrm{x}}+\mathrm{CO}_{2}
\end{gathered}
$$




$$
\begin{aligned}
& \mathrm{Fe}(\mathrm{OH})_{3} \rightarrow \mathrm{FeOOH}+\mathrm{H}_{2} \mathrm{O} \\
& 2 \mathrm{Fe}(\mathrm{OH})_{3} \rightarrow \mathrm{Fe}_{2} \mathrm{O}_{3}+3 \mathrm{H}_{2} \mathrm{O}
\end{aligned}
$$

X-ray diffraction patterns (Figure S1) did not show any specific diffraction peaks of Fe oxides, which could be explained by the high dispersity of the Fe oxides particles and the relatively low Fe loading content (around 1.5\% determined by ICP-9000) [22]. The XPS (X-ray photoelectron spectroscopy) spectra of Fe@CC were shown in Figure 1. The peaks at $710.98 \mathrm{eV}$ and $724.50 \mathrm{eV}$ correspond to the binding energy of $\mathrm{Fe} 2 \mathrm{P}_{3 / 2}$ and $\mathrm{Fe} 2 \mathrm{P}_{1 / 2}$ respectively in $\mathrm{Fe}_{2} \mathrm{O}_{3}$ according to the literatures [23]. As shown in Figure 1A, the spectra peaks at $712.20 \mathrm{eV}$ correspond to the binding energy of $\mathrm{Fe} 2 \mathrm{P}_{3 / 2}$ in FeOOH [24-27]. In Figure 1B, the $\mathrm{O} 1 \mathrm{~s}$ peak of binding energy at $530.20 \mathrm{eV}$ represents the lattice oxygen in iron (III) oxide, and the peak at $531.50 \mathrm{eV}$ represents the hydroxyl group linked with $\mathrm{Fe}(\mathrm{III})$ [28]. According to the relative larger peak area at $712.2 \mathrm{eV}$ than that of $710.98 \mathrm{eV}$, the Fe element on the surface of carbon cloth was mainly in the form of $\mathrm{FeOOH}$.
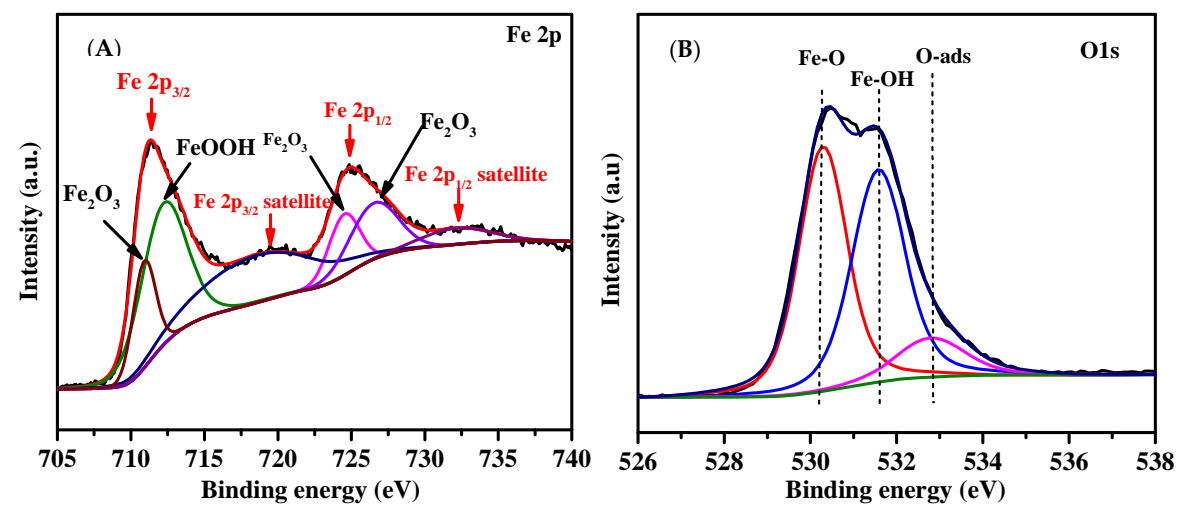

Figure 1. (A) Fe 2p XPS spectra of Fe@CC, and (B) O 1s XPS spectra of Fe@CC.

Temperature is an important factor that dominates the hydrothermal reactions. Figure 2A shows the $\mathrm{N}_{2}$ isothermal adsorption desorption curves of the untreated carbon cloth and the Fe@CC prepared in $160{ }^{\circ} \mathrm{C}, 180^{\circ} \mathrm{C}$ and $200{ }^{\circ} \mathrm{C}$ hydrothermal reactions, respectively. The $\mathrm{N}_{2}$ isothermal adsorption desorption curves of untreated carbon cloth belongs to the type I curve. It is the microporous type isothermal. As shown in Table 1, the total pore volume of carbon cloth is $0.379 \mathrm{~mL} / \mathrm{g}$, in which the microporous volume contributes $0.332 \mathrm{~mL} / \mathrm{g}$. When the carbon cloth was hydrothermal treated in $0.1 \mathrm{M} \mathrm{Fe}\left(\mathrm{NO}_{3}\right)_{3}$, the isothermal curves turned to be type IV, which suggests the coexistence of micropores and mesoporous in the corresponding sample. The mesoporous feature was becoming more obvious when the hydrothermal temperature was increased from $160{ }^{\circ} \mathrm{C}$ to $200{ }^{\circ} \mathrm{C}$. As shown in Table 1, the mesoporous volume increased from $0.095 \mathrm{~mL} / \mathrm{g}$ to $0.224 \mathrm{~mL} / \mathrm{g}$. The micropore volume also increased from $0.377 \mathrm{~mL} / \mathrm{g}$ to $0.627 \mathrm{~mL} / \mathrm{g}$. The specific surface area $\left(\mathrm{S}_{\mathrm{BET}}\right)$ of the as-prepared Fe@CC increased from 826.4 to $1325.5 \mathrm{~m}^{2} / \mathrm{g}$ when the temperature increased from $160{ }^{\circ} \mathrm{C}$ to $200{ }^{\circ} \mathrm{C}$ with $0.1 \mathrm{M} \mathrm{Fe}\left(\mathrm{NO}_{3}\right)_{3}$. The $\mathrm{S}_{\mathrm{BET}}$ of Fe@CC obtained at $200{ }^{\circ} \mathrm{C}$ increased by $81.8 \%$ compared with that of raw carbon cloth $\left(728.9 \mathrm{~m}^{2} / \mathrm{g}\right)$. In order to check whether the increase of $\mathrm{S}_{\mathrm{BET}}$ of Fe@CC was attributed to the hydrothermal acidification of $\mathrm{HNO}_{3}$ produced by the hydrolysis of $\mathrm{Fe}\left(\mathrm{NO}_{3}\right)_{3}$, or the formation of $\mathrm{FeOOH} / \mathrm{Fe}_{2} \mathrm{O}_{3}$ particles loaded on the surface of carbon cloth, the carbon cloth was hydrothermal treated at $200{ }^{\circ} \mathrm{C}$ with different concentration of $\mathrm{HNO}_{3}$, and the isothermal adsorption desorption curves were shown in Figure 1B. It increased to $682.5 \mathrm{~m}^{2} / \mathrm{g}$ and $740.6 \mathrm{~m}^{2} / \mathrm{g}$ when the $\mathrm{HNO}_{3}$ concentration was $0.1 \mathrm{M}$ and $0.3 \mathrm{M}$, respectively. These data were close to that of untreated carbon cloth. The microporous volumes of these two samples were close to that of the untreated carbon cloth, and the mesoporous volumes increased slightly. These data suggested that the acidification of carbon cloth with $\mathrm{HNO}_{3}$ was not the reason responsible for the dramatic increase of specific surface area of the iron oxides loaded carbon cloth. When the $\mathrm{Fe}\left(\mathrm{NO}_{3}\right)_{3}$ concentration was $0.04 \mathrm{M}$, the corresponding 
Fe@CC was $823.3 \mathrm{~m}^{2} / \mathrm{g}$, which was clearly higher than that of the untreated carbon cloth. Meanwhile, the microporous volume and mesoporous volume increased clearly. The increase of microporous and mesoporous volumes could be positive to the catalytic capacity [20]. The specific surface area of $\mathrm{FeOOH} / \mathrm{Fe}_{2} \mathrm{O}_{3}$ nanoparticles prepared by the same hydrothermal reactions without using carbon cloth as the support was $25.3 \mathrm{~m}^{2} / \mathrm{g}$ determined by $\mathrm{N}_{2}$ adsorption and desorption curves (Figure $\mathrm{S} 2$ ). These data suggested that the increase of $\mathrm{S}_{\mathrm{BET}}$ was due to the highly dispersed $\mathrm{FeOOH} / \mathrm{Fe}_{2} \mathrm{O}_{3}$ nanoparticles. Figure 3A,B showed the scan electronic microscope images of Fe@CC obtained at $160{ }^{\circ} \mathrm{C}$ and $200{ }^{\circ} \mathrm{C}$, respectively. It is clearly shown that the loading number of $\mathrm{FeOOH} / \mathrm{Fe}_{2} \mathrm{O}_{3}$ particles is clearly higher at $200^{\circ} \mathrm{C}$, and it is consistent with the $S_{\mathrm{BET}}$ data shown in Table 1.
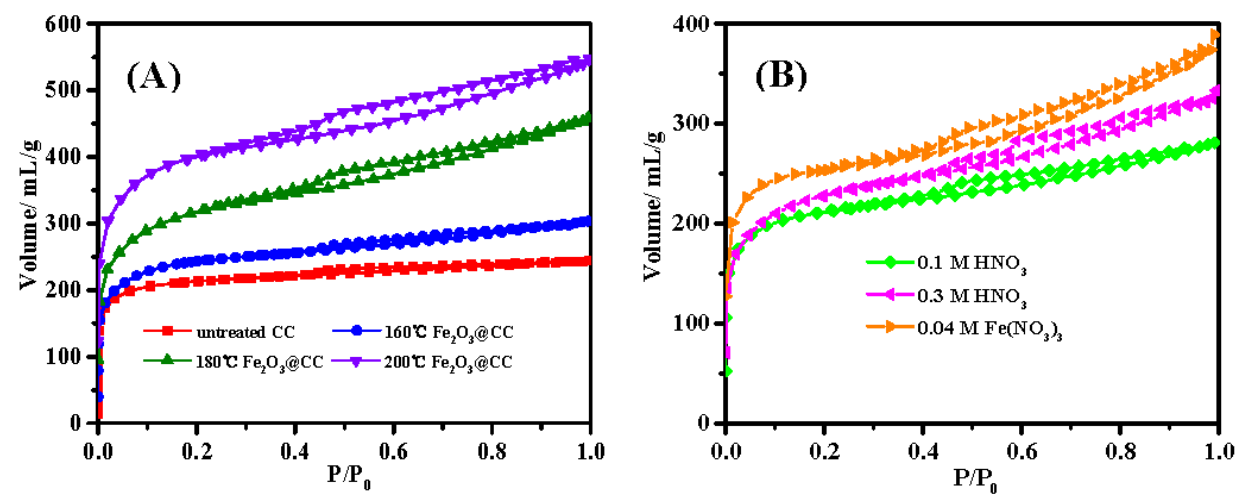

Figure 2. Isothermal adsorption and desorption curves of (A) untreated carbon cloth, hydrothermal treated carbon cloth in $0.1 \mathrm{M} \mathrm{Fe}\left(\mathrm{NO}_{3}\right)_{3}$ at $160^{\circ} \mathrm{C}, 180{ }^{\circ} \mathrm{C}$ and $200{ }^{\circ} \mathrm{C}$, and $(\mathrm{B})$ hydrothermal treated carbon cloth at $200{ }^{\circ} \mathrm{C}$ in $0.1 \mathrm{M} \mathrm{HNO}_{3}, 0.3 \mathrm{M} \mathrm{HNO}_{3}$ and $0.04 \mathrm{M} \mathrm{Fe}\left(\mathrm{NO}_{3}\right)_{3}$ respectively.

Table 1. Parameters of samples determined by Brunauer-Emmett-Teller $\mathrm{N}_{2}$ adsorption and desorption method.

\begin{tabular}{cccccc}
\hline Reagents & $\begin{array}{c}\mathbf{T} \\
{ }^{\circ} \mathbf{C}\end{array}$ & $\begin{array}{c}\mathbf{S}_{\text {BET }} \\
\mathbf{m}^{2} / \mathbf{g}\end{array}$ & $\begin{array}{c}\text { TPV } \\
\mathbf{m L} / \mathbf{g}\end{array}$ & $\begin{array}{c}\mathbf{M P V} \\
\mathbf{m L} / \mathbf{g}\end{array}$ & $\begin{array}{c}\text { MesoPV } \\
\mathbf{m L} / \mathbf{g}\end{array}$ \\
\hline- & - & 728.9 & 0.379 & 0.332 & 0.047 \\
$\mathrm{Fe}\left(\mathrm{NO}_{3}\right)_{3} 0.1 \mathrm{M}$ & 160 & 826.4 & 0.472 & 0.377 & 0.095 \\
$\mathrm{Fe}\left(\mathrm{NO}_{3}\right)_{3} 0.1 \mathrm{M}$ & 180 & 1047.6 & 0.713 & 0.498 & 0.215 \\
$\mathrm{Fe}\left(\mathrm{NO}_{3}\right)_{3} 0.1 \mathrm{M}$ & 200 & 1325.5 & 0.850 & 0.627 & 0.224 \\
$\mathrm{Fe}\left(\mathrm{NO}_{3}\right)_{3} 0.04 \mathrm{M}$ & 200 & 823.3 & 0.605 & 0.394 & 0.210 \\
$\mathrm{HNO}_{3} 0.1 \mathrm{M}$ & 200 & 682.6 & 0.437 & 0.331 & 0.106 \\
$\mathrm{HNO}_{3} 0.3 \mathrm{M}$ & 200 & 740.6 & 0.518 & 0.354 & 0.164 \\
\hline
\end{tabular}

TPV: Total pore volume; MPV: Micropore volume; MesoPV: Mesoporous volume.

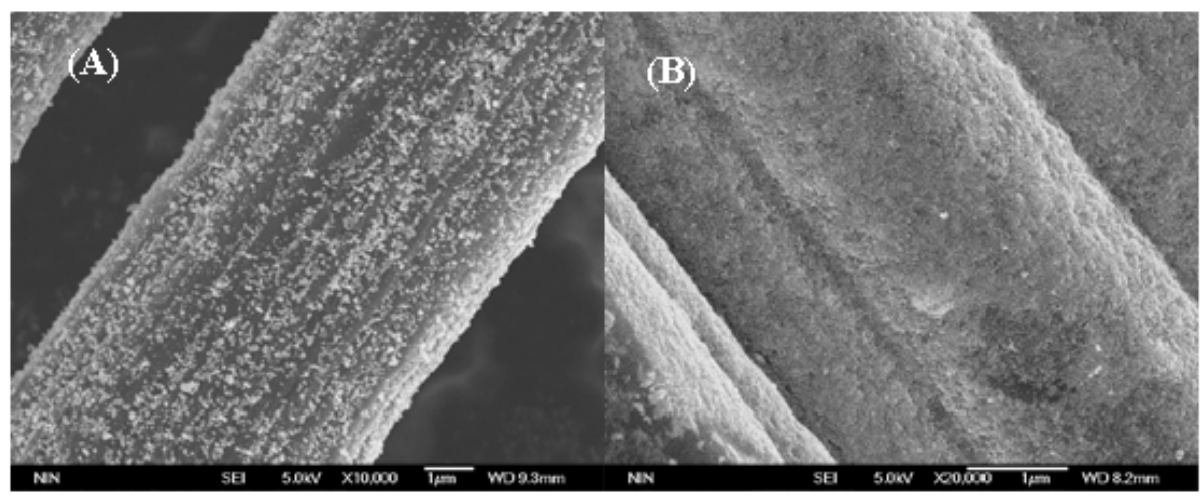

Figure 3. Scan electronic microscope images of Fe@CC obtained at (A) $160{ }^{\circ} \mathrm{C},(\mathbf{B}) 200^{\circ} \mathrm{C}$. 


\subsection{Effect of $\mathrm{pH}$ Value on Catalytic Activity}

In heterogeneous Fenton-like reaction, $\mathrm{pH}$ value affects the reaction activity dramatically as shown in previous reports. Figure $4 \mathrm{~A}$ shows the decolorization curves of Acid Red G (ARG) at the $\mathrm{pH}$ value range of 1.54-4.11. The degradation rate of $\mathrm{ARG}$ at lower $\mathrm{pH}$ value was faster than those at higher $\mathrm{pH}$ values. When fitting the data in Figure 4A with the first order reaction equation [29], the data points obtained as shown in Figure 4B were linear when the $\mathrm{pH}$ value was lower than 3.01. These results suggest that the degradation of ARG followed first order reaction equation. But the data were not linear perfectly. This could be attributed to the adsorption of ARG on the surface of Fe@CC. Furthermore, at higher $\mathrm{pH}$ value ( $>3.01$ ), the decolorization rates of the solution were still relatively high. The data points are not linear, and the decolorization of ARG did not fit the first order reaction anymore. These results also suggest that the adsorption dominated the decolorization at the beginning.
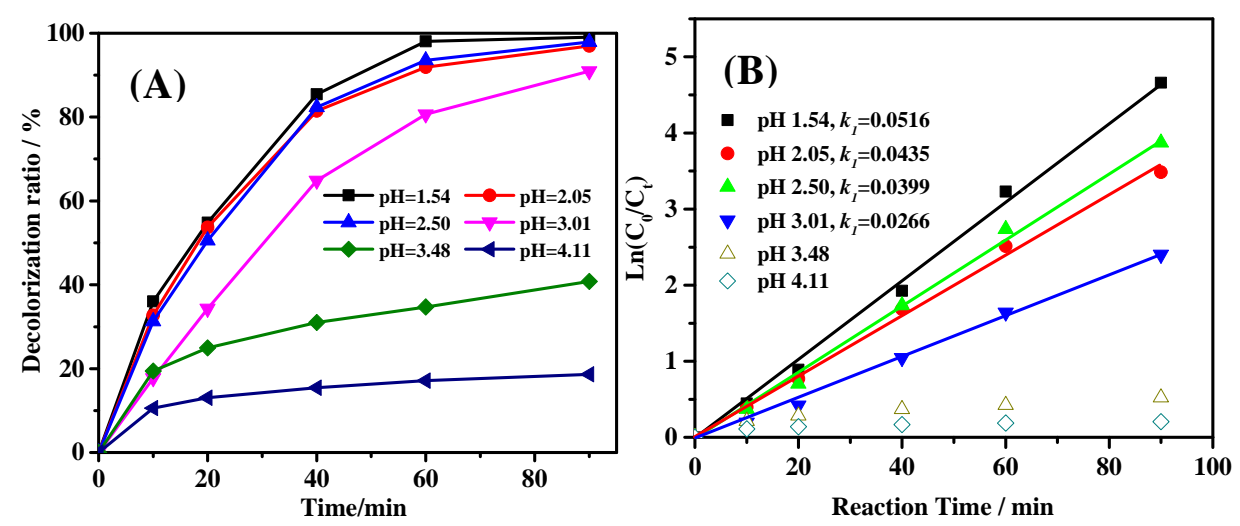

Figure 4. Effect of $\mathrm{pH}$ value on the degradation of $\mathrm{ARG}\left(\mathrm{C}_{0}=50 \mathrm{mg} / \mathrm{L}\right)(\mathrm{A})$, and the first order simulation of the data (B).

At lower $\mathrm{pH}$ value, the leaching amount of iron ions was higher than those at higher $\mathrm{pH}$ value [30]. The leached iron ions dissolved in solution take part in Fenton reaction, and therefore could promote the reaction rate [19]. In this work, the rate constant $k_{1}$ decreased from $0.0516 \mathrm{~min}^{-1}$ to $0.0266 \mathrm{~min}^{-1}$ when the $\mathrm{pH}$ value was increased from 1.54 to 3.01 . In addition, the reaction rate decreased clearly at $\mathrm{pH}$ 3.48. considering the reaction rate and acidification of the solution, the $\mathrm{pH}$ value for most of the iron-based heterogeneous Fenton-like reactions were set around 2.0-3.0 [29,31], therefore, the $\mathrm{pH}$ value was set at 2.50 for further study in this work.

\subsection{Effect of $\mathrm{H}_{2} \mathrm{O}_{2}$ Dosage on Catalytic Activity}

In Fenton and Fenton-like reaction, $\mathrm{H}_{2} \mathrm{O}_{2}$ is the oxidant used for pollutants removal. In theory, one mole of $\mathrm{H}_{2} \mathrm{O}_{2}$ equals to half a mole of oxygen molecules according to the reaction equations [32]. However, in Fenton and Fenton-like reactions, $\mathrm{H}_{2} \mathrm{O}_{2}$ could react with hydroxyl radicals, which leads to the low $\mathrm{H}_{2} \mathrm{O}_{2}$ utilization efficiency [33]. Therefore, it is significant to study the effect of $\mathrm{H}_{2} \mathrm{O}_{2}$ concentration on the degradation efficiency of pollutants. Figure 5A shows the ARG degradation curves at the $\mathrm{H}_{2} \mathrm{O}_{2}$ dosage ranging from $2 \mathrm{mM}$ to $8 \mathrm{mM}$. The degradation rate of ARG increased along with the increase of $\mathrm{H}_{2} \mathrm{O}_{2}$ concentration. As shown in Figure $5 \mathrm{~B}$, the reaction rate constant $k_{1}$ almost increased linearly with the increase of $\mathrm{H}_{2} \mathrm{O}_{2}$ concentration. The results suggest that at this range of $\mathrm{H}_{2} \mathrm{O}_{2}$ concentration, the reaction between hydroxyl radicals and $\mathrm{H}_{2} \mathrm{O}_{2}$ could be negligible [34]. Considering the close decolorization rate using 4, 6 and $8 \mathrm{mM} \mathrm{H}_{2} \mathrm{O}_{2}, 4 \mathrm{mM} \mathrm{H}_{2} \mathrm{O}_{2}$ was chosen for further study. 

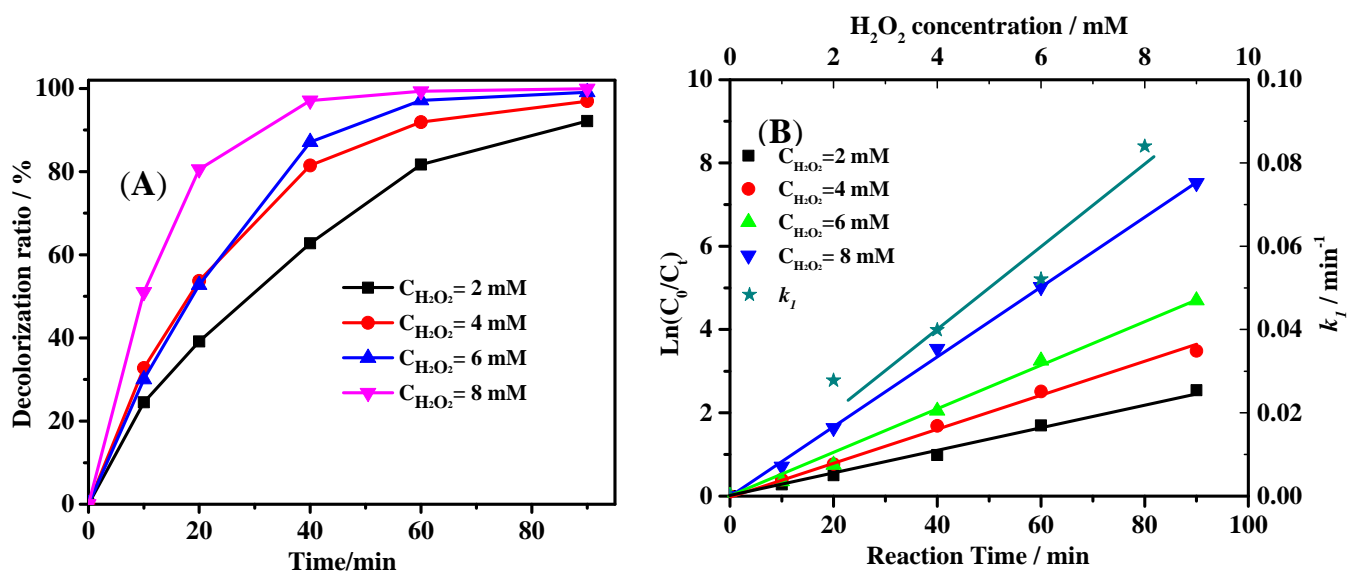

Figure 5. Effect of $\mathrm{H}_{2} \mathrm{O}_{2}$ dosage on the degradation activity of $\mathrm{ARG}\left(\mathrm{C}_{0}=50 \mathrm{mg} / \mathrm{L}, \mathrm{pH}=2.50\right)(\mathbf{A})$, and the first order reaction simulation of the data $(\mathbf{B})$.

\subsection{Heterogeneous and Homogeneous Fenton Reaction}

Methanol is a commonly used radical scavenger to determine the contribution of the hydroxyl radical during heterogeneous Fenton-like reaction $\left(K_{H O}=1.2-2.8 \times 10^{9} \mathrm{M}^{-1} \cdot \mathrm{s}^{-1}\right)[32,35,36]$. As shown in Figure $6 \mathrm{~A}$, the addition of $0.1 \mathrm{M}$ and $0.5 \mathrm{M}$ methanol reduced the decolorization rate by $18.2 \%$ and $38.7 \%$. These results suggested that $\mathrm{HO}$. in the solution played important role on decolorization. However, since the mole ratios of methanol to ARG were 1000:1 and 5000:1, the decrease of decolorization rate was relatively low. It suggests that large amount of ARG was degraded on the surface of Fe@CC benefiting from the high specific surface and the adsorption of ARG. The Fe ions leached in the reaction solution is determined to be $0.20-0.40 \mathrm{mg} / \mathrm{L}$ by ICP-9000. The results of homogeneous Fenton reaction with $0.20 \mathrm{ppm}$ and $0.40 \mathrm{ppm} \mathrm{Fe}{ }^{3+}\left(\mathrm{FeCl}_{3}\right.$ as the $\mathrm{Fe}$ (III) source) for ARG decolorization is shown in Figure 6B. The data showed that the decolorization rates of ARG solution were $58.5 \%$ and $82.2 \%$, which were lower than that of $99.1 \%$ with the Fe@CC. When $0.1 \mathrm{M}$ methanol was added, the decolorization rates of the homogeneous reactions with $0.2 \mathrm{ppm}$ or $0.4 \mathrm{ppm}$ $\mathrm{Fe}^{3+}$ decreased to $0.8 \%$ and $2.6 \%$, respectively. These results further confirmed that the decolorization of ARG with Fe@CC occurred on the surface of the catalyst, and the homogeneous Fenton reaction in the tests using Fe@CC as catalyst was not dominated.

The decolorization profile using $8.8 \mathrm{mg} \mathrm{FeOOH} / \mathrm{Fe}_{2} \mathrm{O}_{3}$ prepared with the same hydrothermal method using for Fe@CC preparation is shown in Figure 6A. The iron content in $8.8 \mathrm{mg} \mathrm{FeOOH} / \mathrm{Fe}_{2} \mathrm{O}_{3}$ was the same with that in $0.2 \mathrm{~g}$ Fe@CC used for catalysis. In addition, the decolorization rate was $14.1 \%$, which was clearly lower than that of 99.1\% using Fe@CC. The results suggested that the loading of Fe oxide on carbon cloth with high dispersity enhanced the activity. In this work, the high specific surface area also promotes the reaction via adsorption [20].

The significance of homogeneous reaction with leached iron ions was further studied by sampling the reaction liquid after Fenton-like reaction with Fe@CC as shown in Figure S3A. The reaction rates reduced clearly after the Fe@CC was removed from the solution, and the rate constant was at the range of $0.0038-0.0111$ as shown in Figure S3B, which were lower than that of $0.0399 \mathrm{~min}^{-1}$ obtained with Fe@CC. The concentration of iron ions leached in the solution increased along with the extension of reaction time as shown in Figure S4, and reached $0.33 \mathrm{mg} / \mathrm{L}$, which was lower than that of $0.84 \mathrm{mg} / \mathrm{L}-1.008 \mathrm{mg} / \mathrm{L}$ obtained by Guo et al. [37] and that of $0.85 \mathrm{mg} / \mathrm{L}-0.95 \mathrm{mg} / \mathrm{L}$ obtained by Du et al. [38], and it is close to that obtained by Rache et al. [30]. The results suggested that the Fe@CC showed higher stability than the previous results.

It is reported that carbon materials could promote the production of hydroxyl radicals in $\mathrm{Fe}(\mathrm{III}) / \mathrm{H}_{2} \mathrm{O}_{2}$ Fenton reaction system [39]. However, in this work, the native carbon cloth did not show any Fenton-like reaction activity as shown in Figure S5. The decolorization efficiency of around 20\% at 
the first run was attributed to the adsorption of ARG on the carbon cloth. The oxidation activity of the heterogeneous catalyst is acknowledged to occur on the surface of the catalyst. This result is not consistent with that reported by Kuan et al. Their report result suggested the dissolved metal ions $\left(\mathrm{Fe}^{3+}\right.$ and $\left.\mathrm{Cu}^{2+}\right)$ contributed significantly on degrading 4-CP [40], especially on neutral $\mathrm{pH}$ value, the leaching of $\mathrm{Fe}^{3+}$ could be suppressed, but the dissolving of $\mathrm{Cu}^{2+}$ could not be suppressed.
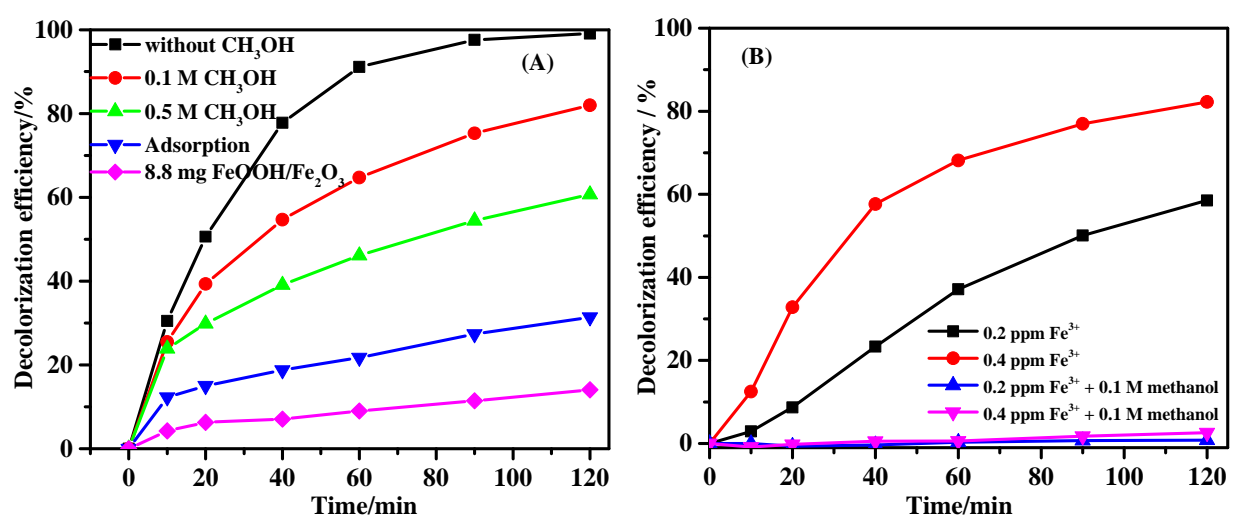

Figure 6. Decolorization of ARG using Fe@CC supplemented with ethanol or using $\mathrm{FeOOH} / \mathrm{Fe}_{2} \mathrm{O}_{3}$ prepared by hydrothermal (A), and decolorization of ARG by homogeneous Fenton reaction using $\mathrm{Fe}^{3+}$ or $\mathrm{Fe}^{3+}$ supplemented with $0.1 \mathrm{M}$ methanol (B).

\subsection{Stability of Catalytic Activity}

One of the major advantage of heterogeneous Fenton-like reaction was the reusability of the catalyst. Therefore, the stability of catalytic activity of the catalyst is significant for practical application. In this work, repeated tests were conducted to determine the decrease of catalytic activity of the as-prepared catalyst. As shown in Figure 7A, the decolorization ratio in two-hour reaction decreased gradually from $96 \%$ at the first test to $80 \%$ at the seventh test and it kept almost constant at the following four tests. The catalytic activity could be maintained at relatively high level and kept stable. The COD (Chemical Oxygen Demand) removal efficiency data during the eleven tests are shown in Figure 7B. The variation of the data could be attributed to variation of COD determination in low COD value range (initial $C_{0}$ of ARG $50 \mathrm{mg} / \mathrm{L}$ equals to $66.5 \mathrm{mg}-\mathrm{COD} / \mathrm{L}$ ). However, all of the COD removal efficiency data are higher than $50 \%$, which suggest that the hydrogen peroxide utilization efficiency of these tests were quite high (the apparent utilization efficiency was around 45\%), and this Fe@CC catalyst could be a potential product for practical application.
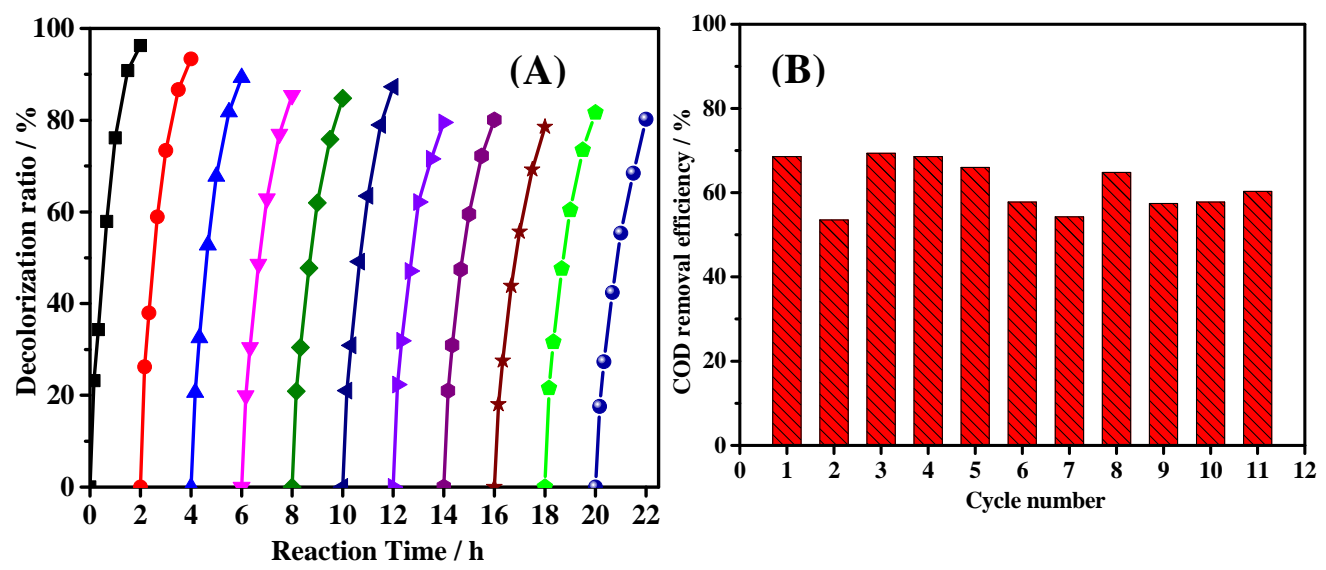

Figure 7. Stability of the catalytic activity $(\mathbf{A})$ and the COD removal efficiency $(\mathbf{B})$ during 11 repeats, $\mathrm{C}_{0}(\mathrm{ARG})=50 \mathrm{mg} / \mathrm{L}, \mathrm{C}_{0}\left(\mathrm{H}_{2} \mathrm{O}_{2}\right)=4 \mathrm{mM}$. 
The moderate decrease of catalytic activity during the several tests at the beginning was also observed in many literatures $[21,35,41]$. However, no reasonable explanation for the decrease of catalytic activity was addressed in these reports. Since Fe@CC possesses high specific surface area, one hypothesis could be that the initial adsorption capacity of this material enhanced the decolorization rate of the reaction. The adsorption of the fresh Fe@CC led to 31\% of decolorization ratio, and this figure turned to be $6 \%$ after four cycle tests as shown in Figure 8A. As shown in Figure 8B, the decolorization ratio decreased gradually from $95 \%$ at the first test to $90 \%$ at the fourth test, and it recovered to $97 \%$ after calcination at $300{ }^{\circ} \mathrm{C}$ for $1 \mathrm{~h}$. Meanwhile, the adsorption performance of the sample recovered to that close to the fresh sample. This result indicates that the adsorption of ARG on the surface of Fe@CC promoted its degradation. In the heterogeneous Fenton-like reaction, the process is of highly oxidation, and the homogeneous Fenton reaction exists due to the leaching of iron ions. Therefore, the possibility for the occupation of the catalyst surface by ARG molecules during the reaction is quite low, and we also did not detect the molecules attached on the surface of Fe@CC by FTIR (Flourier transformed Infrared Spectroscopy) (data not shown). The decrease of adsorption capacity of Fe@CC after several tests could be attributed to the change of surface state.
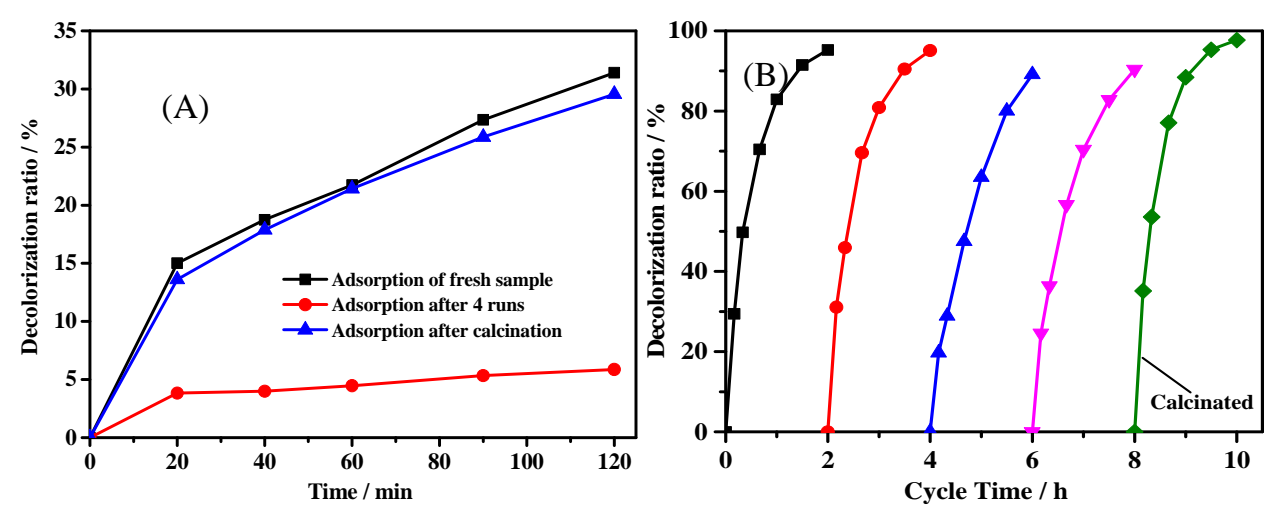

Figure 8. (A) Adsorption curves of fresh sample, the sample after 4 tests, and the sample calcinated after 4 tests, (B) repeated tests of $\mathrm{Fe}_{2} \mathrm{O}_{3} @ \mathrm{CC}$ and the recovery of activity after calcination at $300{ }^{\circ} \mathrm{C}$ for $1 \mathrm{~h}$.

The catalytic activity of Fe@CC was higher than the previous report by using fine activated carbon powders as the supporter and $\mathrm{Fe}\left(\mathrm{NO}_{3}\right)_{3}$ as the iron source [19], and it is easier to separate compared with fine activated carbon particles. Iron oxides loaded on activated carbon with iron (II) acetate as the precursor showed completely decomposition of $0.1 \mathrm{M}$ Orange II dye $\left(6-24 \mathrm{mM} \mathrm{H}_{2} \mathrm{O}_{2}\right)$ in $5 \mathrm{~h}$, and its catalytic activity was apparently lower than the data obtained in the current study [20].

Figure 9 shows the zeta potential of Fe@CC before and after reaction. The carbon cloth without treatment was negatively charged at the $\mathrm{pH}$ range of 2-6. It moved to positive charged status when Fe oxide was loaded via hydrothermal reaction at the $\mathrm{pH}$ range of 2-2.5. The zeta potential data of Fe@CC were close to zero $\mathrm{mV}$ at the $\mathrm{pH}$ range of 2-2.5 after four tests, and meanwhile the catalysts showed reduced activity. ARG is an anionic dye with negatively charged molecule, and therefore the fresh catalyst showed higher adsorption performance for ARG via electrostatic interactions as shown in Figure 7A, and after four tests, somehow the zeta potential of the Fe@CC surface was negatively moved and therefore the electrostatic interactions were reduced and led to lower adsorption performance for ARG. After calcination, the zeta potential data were recovered to be close to those of the fresh $\mathrm{Fe}_{2} \mathrm{O}_{3} @ \mathrm{CC}$, and the adsorption capacity was recovered. ARG molecules with negatively charged is repelled by the electrostatic repulsion due to the negatively charged surface of Fe@CC. In addition, this could be the reason for the relatively poor adsorption capacity of ARG on Fe@CC based on the large specific surface area of this material $\left(\mathrm{S}_{\mathrm{BET}}=1325 \mathrm{~m}^{2} / \mathrm{g}\right)$. 


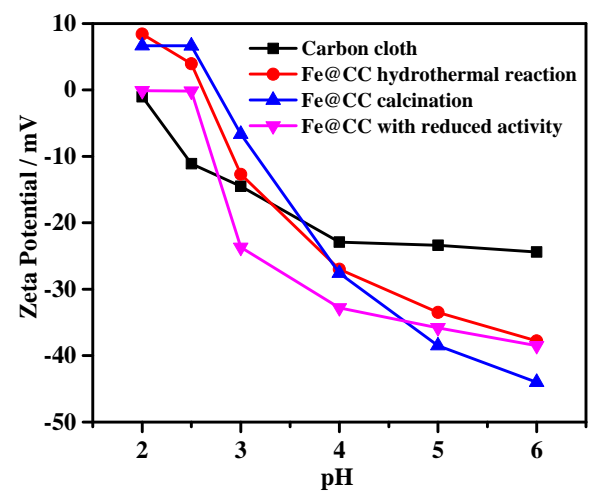

Figure 9. Zeta potential of the carbon cloth without treatment, Fe@CC after hydrothermal reaction at $200{ }^{\circ} \mathrm{C}, \mathrm{Fe} @ \mathrm{CC}$ after calcination at $300^{\circ} \mathrm{C}$ and Fe@CC with reduced activity.

Iron ions leaching is inevitable in the heterogeneous Fenton-like reaction with iron-based catalyst. The Fe content of the fresh Fe@CC sample used in Figure 5 was $15.4 \mathrm{mg} / \mathrm{g}$, and it reduced to $8.4 \mathrm{mg} / \mathrm{g}$ after 5 tests, and it reduced to $4.80 \mathrm{mg} / \mathrm{g}$ after 11 tests. The decolorization ratio only decreased by $12 \%$ after 5 tests, and it reduced by $16.7 \%$ after 11 tests. It suggested that the catalytic activity of Fe@CC could maintain at relatively high level until the iron that loaded on the surface of carbon cloth was depleted. Figure 10 shows the morphology of carbon cloth and Fe@CC. As shown in Figure 10B, the Fe oxide particles on the carbon cloth in the fresh catalyst were highly dispersed and tightly attached, as the surface status was completely changed compared with the native carbon cloth as shown in Figure 10A. After five tests, the loading amount of Fe oxide on the carbon cloth was less than the fresh sample as shown in Figure 10C. The loading amount of Fe oxide further decreased after 11 tests as shown in Figure 10D. The particles on the edge were reduced more quickly than those in the corner. The raw carbon cloth possesses large amount of micropores as shown in Table 1 . These pores could be filled with Fe oxides as shown in Table 1 that the micropores volume was decreased clearly when Fe oxide was loaded. These $\mathrm{FeOOH} / \mathrm{Fe}_{2} \mathrm{O}_{3}$ particles were highly dispersed and could be highly active in Fenton-like reaction. The leaching of these $\mathrm{FeOOH} / \mathrm{Fe}_{2} \mathrm{O}_{3}$ might be much slower than those on the edge, and these features could be the reasons for the high activity and stability of Fe@CC.

The concentration of iron ions in the reaction solution determined by ICP-9000 was around $0.20-0.40 \mathrm{mg} / \mathrm{L}$, and the amount of iron ions leached into the solution during the 11 tests was $1.1 \mathrm{mg} / \mathrm{g}$-CC according to the calculation based on the $\mathrm{Fe}(\mathrm{III})$ concentration in the reaction solution. This datum is quite lower than that of $10.6 \mathrm{mg} / \mathrm{g}$-CC according to the initial and final loading amount of Fe oxide after 11 tests, and this result suggested that some of the Fe oxide could be peeled off from the carbon cloth due to the shearing force created by the shaking of the reaction bottle in the table concentrator. Therefore, reinforce of the attachment between $\mathrm{FeOOH} / \mathrm{Fe}_{2} \mathrm{O}_{3}$ and the carriers should be further studied.
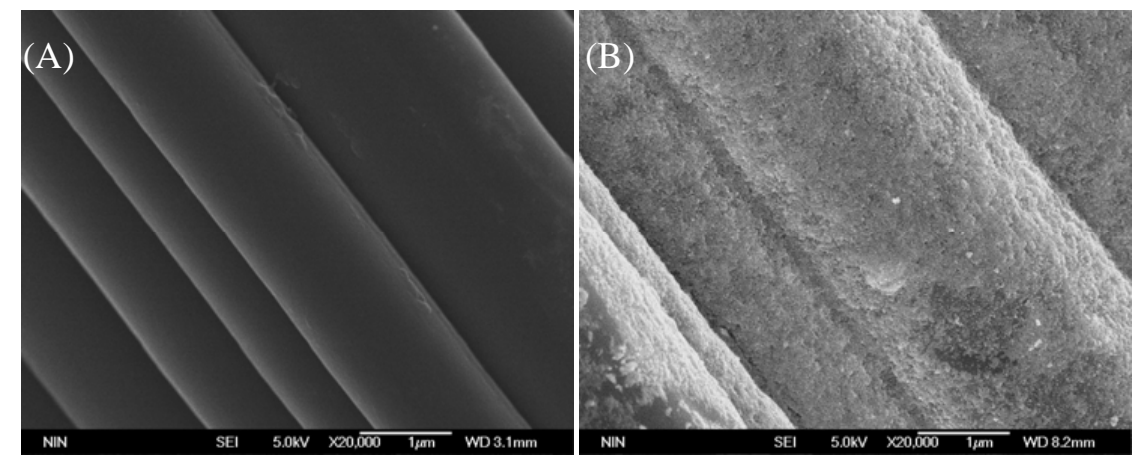

Figure 10. Cont. 


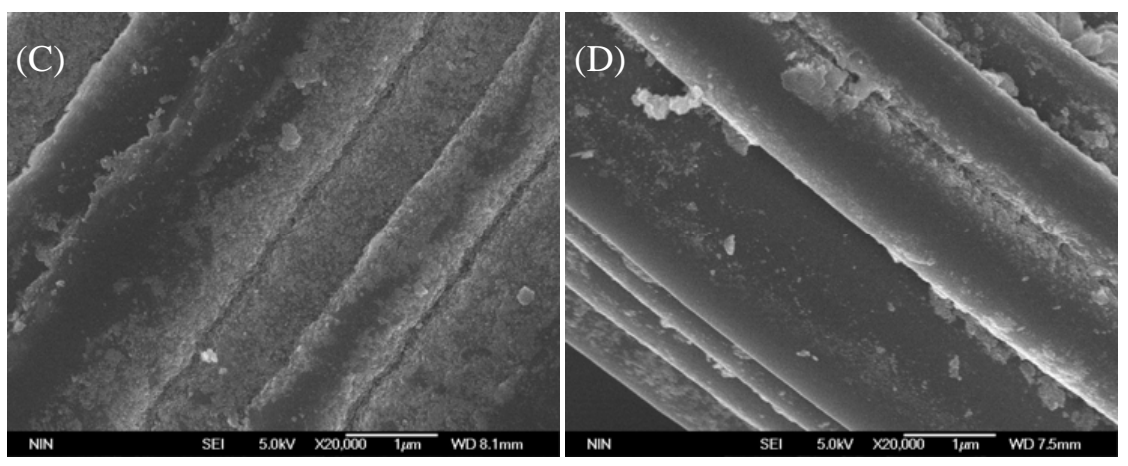

Figure 10. Scan Electronic Microscope patterns of carbon cloth (A) and Fe@CC of fresh prepared with hydro-thermal reaction (B), after 5 times reaction $(\mathbf{C})$, and after 11 times reaction (D).

\section{Materials and Methods}

\subsection{Reagents}

The chemicals used in this study were purchased from Sinopharm Chemical Reagent Co. Ltd., including Acid Red G (ARG), $\mathrm{Fe}\left(\mathrm{NO}_{3}\right)_{3} \cdot 9 \mathrm{H}_{2} \mathrm{O}$, hydrochloric acid $(\mathrm{HCl})$, hydrogen peroxide $\left(\mathrm{H}_{2} \mathrm{O}_{2}\right.$, $30 \mathrm{wt} \%)$, Methanol $\left(\mathrm{CH}_{3} \mathrm{OH}\right)$, nitric acid $\left(\mathrm{HNO}_{3}\right)$. The carbon cloth was purchased from commercial market (Shanghai Hesen Co. Ltd., Shanghai, China, derived from activated carbon fibers). All chemicals were analytical grade without further purification.

\subsection{Catalysts Preparation}

$50 \mathrm{~mL} \mathrm{Fe}\left(\mathrm{NO}_{3}\right)_{3}$ with concentration between $0.005 \mathrm{M}$ and $0.1 \mathrm{M}$ was set in a stainless steel hydrothermal reactor with $70 \mathrm{~mL}$ Teflon inner container, and the reactor was sealed after $1.00 \mathrm{~g}$ carbon cloth was immersed into the solution. The reactor was heated in an oven set at $160{ }^{\circ} \mathrm{C}, 180^{\circ} \mathrm{C}$ or $200^{\circ} \mathrm{C}$ for $3 \mathrm{~h}$, respectively. The carbon cloth was washed with distill water under ultrasonic washing for $1 \mathrm{~min}\left(40 \mathrm{~K}, 0.5 \mathrm{~W} / \mathrm{cm}^{2}\right)$ to remove the unloaded ferrous oxide. The carbon cloth was washed with distill water until the washing liquid was clear and transparent. The washed carbon cloth was dried in a $60{ }^{\circ} \mathrm{C}$ oven. The obtained samples were assigned as Fe@CC.

For reference, $\mathrm{Fe}$ oxide was prepared using the same hydrothermal reaction at $200{ }^{\circ} \mathrm{C}$ for $3 \mathrm{~h}$ without using carbon cloth as the support.

\subsection{Catalytic Reaction}

The Fenton-like reactions were conducted in $150 \mathrm{~mL}$ narrow neck flasks. In each reaction, $50 \mathrm{~mL}$ $50 \mathrm{ppm}$ Acid Red G (ARG) with proper $\mathrm{pH}$ value adjusted using $0.1 \mathrm{M} \mathrm{NaOH}$ and $0.1 \mathrm{M} \mathrm{HCl}, 0.20 \mathrm{~g}$ Fe@CC, and proper volume of hydrogen peroxide $(10-60 \mu \mathrm{L})$ were added in the flask. The reactors were placed in a table concentrator controlled at $30 \pm 0.5^{\circ} \mathrm{C}$ and $150 \mathrm{rpm}$. The reaction was sampled in every 10-20 $\mathrm{min}$, and the samples were filtrated by a $0.45 \mu \mathrm{m}$ syringe filter hydrophilic membrane to eliminate the particles that may detached from Fe@CC. The concentration of the ARG was determined by spectrophotometry on a spectrophotometer according to the following formula (5).

$$
D_{\text {COLOR }} \%=\left(A_{0}-A_{t}\right) / A_{0} \times 100 \%
$$

where $D_{\mathrm{COLOR}} \%$ is decolorization ratio of the ARG solution during Fenton-like reaction. $A_{0}$ is the absorption of the initial ARG solution (50 ppm) at $504 \mathrm{~nm}$, and $A_{t}$ represents the absorption of the ARG solution at time $t$ during reaction.

In order to check the homogenous Fenton reaction conducted by the leached iron ions during reaction, $300 \mathrm{~mL}$ ARG solution $(50 \mathrm{mg} / \mathrm{L})$ with $0.2 \mathrm{~g} \times 6 \mathrm{Fe} @ \mathrm{CC}$ was used as reaction solution and catalyst. At the beginning, ARG solution mixed with $1.2 \mathrm{~g}$ Fe@CC and $120 \mu \mathrm{L} \mathrm{H}_{2} \mathrm{O}_{2}$ was reacted in a 
table concentrator controlled at $30 \pm 0.5^{\circ} \mathrm{C}$ and $150 \mathrm{rpm}$, and $50 \mathrm{~mL}$ mixture and $0.2 \mathrm{~g}$ Fe@CC were sampled after a set time interval. The sampled $50 \mathrm{~mL}$ mixture was filtrated with $0.45 \mu \mathrm{m}$ syringe filter hydrophilic membrane to remove the catalyst particles that may remained in the mixture, and the 50-mL filtrated mixture was placed in the same table concentrator for further reaction.

Homogenous Fenton reactions were also conduced to check the significance of leached iron ions on degradation. According to the iron ions concentration determined by Inductively Coupled Plasma Optical Emission Spectrometry (ICP-OES-9000, Shimadzu Ltd., Tokyo, Japan), proper amount of $\mathrm{Fe}\left(\mathrm{NO}_{3}\right)_{3}$ was mixed with ARG solution and $\mathrm{H}_{2} \mathrm{O}_{2}$, and the reactions were conducted at the same condition described above.

\subsection{Characterization}

The specific surface area (SSA) of the catalysts were determined on a SSA analyzer (SSA-4300, Beijing Builder Electronic Technology Co., Ltd., Beijing, China) using nitrogen adsorption-desorption method at $77 \mathrm{~K}$ (Brunauer-Emmett-Teller method), and the pore volumes were calculated by Barrett-Joyner-Halenda method offered by the equipment. Before the SSA determination, the Fe@CC samples were degassed at $105^{\circ} \mathrm{C}$ for $2 \mathrm{~h}$. The XRD (X-ray diffraction spectra) patterns were obtained on an X-ray diffractor (PANalytical, X'pert MPD Pro X) using $\mathrm{Cu} \mathrm{K} \alpha$ radiation at $40 \mathrm{kV}$ and $40 \mathrm{~mA}$. The surface morphology of the Fe@CC was observed on a scan electronic microscope (JSM-6700F, Japan JEOL, Co. Ltd., Tokyo, Japan). Zeta potential was determined with Malvern Zetasizer Nano ZS90 (British Malvern Instruments Ltd., Malvin city, UK). Samples for zeta potential determination were grinded, and $5 \mathrm{mg}$ of Fe@CC powders was suspended in $10 \mathrm{~mL} 1 \mathrm{mM} \mathrm{NaCl}$ solution, and the $\mathrm{pH}$ value varied from 2 to 6 . For Fe content measurement, about $0.02 \mathrm{~g}$ Fe@CC was dried in a $105^{\circ} \mathrm{C}$ oven until constant weight. The dried sample was then digested with $8 \mathrm{~mL}$ nitrohydrochloric acid assisted by microwave (Multiwave 3000, Anton Paar $\mathrm{GmbH}$ ) at $160^{\circ} \mathrm{C}$ for $1 \mathrm{~h}$. The digested solution was diluted into $100 \mathrm{~mL}$ and the Fe concentration was measured using an ICP-OES-9000. The Fe concentration of the Fenton-like reaction was also determined by ICP-OES-9000.

\section{Conclusions}

In summary, Fe oxide loaded on carbon cloth (Fe@CC) with high specific surface area was synthesized. $\mathrm{Fe}$ oxide including $\mathrm{FeOOH}$ and $\mathrm{Fe}_{2} \mathrm{O}_{3}$ were coated on the surface of carbon cloth with large number of mesoporous pores created by the packing of the particles via hydrothermal hydrolysis of $\mathrm{Fe}\left(\mathrm{NO}_{3}\right)_{3}$ and led to an increase of specific surface area by $81.8 \%$ compared with the carbon cloth. The activity of Fe@CC was stable at Fenton reaction. The degradation of ARG dye molecules mainly occurred on the surface of the catalyst. The gradual decrease of Fenton-like reaction activity during the first four tests was attributed to the decrease of ARG adsorption capacity of Fe@CC due to its negatively moved zeta potential. Fe@CC could still maintain relatively high and stable activity during the 11 tests.

Supplementary Materials: The following are available online at http:/ /www.mdpi.com/2073-4344/8/5/207/s1, Figure S1: XRD patterns of carbon cloth and Fe@CC. 1. Carbon cloth without treatment; 2. Fresh Fe@CC prepared by hydrothermal reaction; 3. Fe@CC calcinated at $300^{\circ} \mathrm{C}$ for $1 \mathrm{~h} ; 4$. Fe@CC after used for 4 tests; 5 . Fe@CC used for 4 tests and then calcinated at $300^{\circ} \mathrm{C}$ for $1 \mathrm{~h}$, Figure S2: Isothermal adsorption and desorption curves of Fe oxide prepared by hydrothermal reaction, Figure S3: (A) Significance of homogeneous reaction, and (B) the rate constants of homogeneous reaction fitted from the data in (A). HetR: fenton reaction with Fe@CC; HomR: homogenous reaction with the leached iron ions, Figure S4: The concentration of iron ions leached in the solution versus reaction time with Fe@CC, Figure S5: Fenton like reaction with carbon cloth as the catalyst.

Author Contributions: H.Y. designed the experiments and wrote the manuscript; B.S. conducted most of the tests; S.W. did some characterization including determining the iron concentration after fenton like reaction, and the SEM characterization.

Acknowledgments: We appreciate the discussion with Yongfang Rao. The authors appreciate the financial support from the National Natural Science Foundation of China for the Youth (No. 51308452).

Conflicts of Interest: The authors declare no conflicts of interest. 


\section{References}

1. Chen, H.; Zhang, L.; Zeng, H.; Yin, D.; Zhai, Q.; Zhao, X.; Li, J. Highly active iron-containing silicotungstate catalyst for heterogeneous Fenton oxidation of 4-chlorophenol. J. Mol. Catal. A Chem. 2015, 406, $72-77$. [CrossRef]

2. Divya, T.; Renuka, N.K. Modulated heterogeneous Fenton-like activity of ' $\mathrm{M}$ ' doped nanoceria systems $(\mathrm{M}=\mathrm{Cu}, \mathrm{Fe}, \mathrm{Zr}, \mathrm{Dy}, \mathrm{La})$ : Influence of reduction potential of doped cations. J. Mol. Catal. A Chem. 2015, 408, 41-47. [CrossRef]

3. Jamalluddin, N.A.; Abdullah, A.Z. Fe incorporated mesocellular foam as an effective and stable catalyst: Effect of Fe concentration on the characteristics and activity in Fenton-like oxidation of acid red B. J. Mol. Catal. A Chem. 2016, 414, 94-107. [CrossRef]

4. Lv, H.; Zhao, H.; Cao, T.; Qian, L.; Wang, Y.; Zhao, G. Efficient degradation of high concentration azo-dye wastewater by heterogeneous Fenton process with iron-based metal-organic framework. J. Mol. Catal. A Chem. 2015, 400, 81-89. [CrossRef]

5. Bicalho, H.A.; Lopez, J.L.; Binatti, I.; Batista, P.F.R.; Ardisson, J.D.; Resende, R.R.; Lorençon, E. Facile synthesis of highly dispersed $\mathrm{Fe}(\mathrm{II})$-doped $\mathrm{g}-\mathrm{C}_{3} \mathrm{~N}_{4}$ and its application in Fenton-like catalysis. Mol. Catal. 2017, 435, 156-165. [CrossRef]

6. Wang, N.; Zheng, T.; Zhang, G.; Wang, P. A review on Fenton-like processes for organic wastewater treatment. J. Environ. Chem. Eng. 2016, 4, 762-787. [CrossRef]

7. Naumczyk, J.; Prokurat, I.; Marcinowski, P. Landfill leachates treatment by $\mathrm{H}_{2} \mathrm{O}_{2} / \mathrm{UV}, \mathrm{O}_{3} / \mathrm{H}_{2} \mathrm{O}_{2}$, modified Fenton, and modified photo-Fenton methods. Int. J. Photoenergy 2012, 2012, 9. [CrossRef]

8. Lopez, A.; Pagano, M.; Volpe, A.; Claudio, D.P.A. Fenton's pre-treatment of mature landfill leachate. Chemosphere 2004, 54, 1005-1010. [CrossRef] [PubMed]

9. Pouran, S.R.; Abdul Raman, A.A.; Wan Daud, W.M.A. Review on the application of modified iron oxides as heterogeneous catalysts in Fenton reactions. J. Clean. Prod. 2014, 64, 24-35. [CrossRef]

10. Cleveland, V.; Bingham, J.-P.; Kan, E. Heterogeneous Fenton degradation of bisphenol A by carbon nanotube-supported $\mathrm{Fe}_{3} \mathrm{O}_{4}$. Sep. Purif. Technol. 2014, 133, 388-395. [CrossRef]

11. Queirós, S.; Morais, V.; Rodrigues, C.S.D.; Maldonado-Hódar, F.J.; Madeira, L.M. Heterogeneous Fenton's oxidation using Fe/ZSM-5 as catalyst in a continuous stirred tank reactor. Sep. Purif. Technol. 2015, 141, 235-245. [CrossRef]

12. Wu, Y.; Zeng, S.; Wang, F.; Megharaj, M.; Naidu, R.; Chen, Z. Heterogeneous Fenton-like oxidation of malachite green by iron-based nanoparticles synthesized by tea extract as a catalyst. Sep. Purif. Technol. 2015, 154, 161-167. [CrossRef]

13. Singh, L.; Rekha, P.; Chand, S. Cu-impregnated zeolite $\mathrm{Y}$ as highly active and stable heterogeneous Fenton-like catalyst for degradation of Congo red dye. Sep. Purif. Technol. 2016, 170, 321-336. [CrossRef]

14. Dantas, T.L.P.; Mendonça, V.P.; José, H.J.; Rodrigues, A.E.; Moreira, R.F.P.M. Treatment of textile wastewater by heterogeneous Fenton process using a new composite $\mathrm{Fe}_{2} \mathrm{O}_{3}$ /carbon. Chem. Eng. J. 2006, 118, 77-82. [CrossRef]

15. An, H.; Su, C.; McGinn, P.J. Application of potash glass as a catalyst for diesel soot oxidation. Catal. Commun. 2009, 10, 509-512. [CrossRef]

16. Su, C.; McGinn, P.J. The effect of $\mathrm{Ca}^{2+}$ and $\mathrm{Al}^{3+}$ additions on the stability of potassium disilicate glass as a soot oxidation catalyst. Appl. Catal. B Environ. 2013, 138-139, 70-78. [CrossRef]

17. Su, C.; McGinn, P.J. Application of glass soot catalysts on metal supports to achieve low soot oxidation temperature. Catal. Commun. 2014, 43, 1-5. [CrossRef]

18. Tong, Z.; Zheng, P.; Bai, B.; Wang, H.; Suo, Y. Adsorption performance of methyl violet via $\alpha-\mathrm{Fe}_{2} \mathrm{O}_{3} @$ porous hollow carbonaceous microspheres and its effective regeneration through a Fenton-Like reaction. Catalysts 2016, 6, 58. [CrossRef]

19. Duarte, F.M.; Maldonado-Hódar, F.J.; Madeira, L.M. Influence of the iron precursor in the preparation of heterogeneous Fe/activated carbon Fenton-like catalysts. Appl. Catal. A Gen. 2013, 458, 39-47. [CrossRef] 
20. Duarte, F.M.; Maldonado-Hódar, F.J.; Madeira, L.M. Influence of the characteristics of carbon materials on their behaviour as heterogeneous Fenton catalysts for the elimination of the azo dye Orange II from aqueous solutions. Appl. Catal. B Environ. 2011, 103, 109-115. [CrossRef]

21. Lan, H.; Wang, A.; Liu, R.; Liu, H.; Qu, J. Heterogeneous photo-Fenton degradation of acid red $\mathrm{B}$ over $\mathrm{Fe}_{2} \mathrm{O}_{3}$ supported on activated carbon fiber. J. Hazard. Mater. 2015, 285, 167-172. [CrossRef] [PubMed]

22. Xiao, F.; Li, W.; Fang, L.; Wang, D. Synthesis of akageneite (beta-FeOOH)/reduced graphene oxide nanocomposites for oxidative decomposition of 2-chlorophenol by Fenton-like reaction. J. Hazard. Mater. 2016, 308, 11-20. [CrossRef] [PubMed]

23. Yamashita, T.; Hayes, P. Analysis of XPS spectra of $\mathrm{Fe}^{2+}$ and $\mathrm{Fe}^{3+}$ ions in oxide materials. Appl. Surf. Sci. 2008, 254, 2441-2449. [CrossRef]

24. Taha, M.R.; Ibrahim, A.H. Characterization of nano zero-valent iron (nZVI) and its application in sono-Fenton process to remove COD in palm oil mill effluent. J. Environ. Chem. Eng. 2014, 2, 1-8. [CrossRef]

25. Sun, Y.-P.; Li, X.-Q.; Cao, J.; Zhang, W.-X.; Wang, H.P. Characterization of zero-valent iron nanoparticles. Adv. Colloid Interface Sci. 2006, 120, 47-56. [CrossRef] [PubMed]

26. Xiao, J.; Gao, B.; Yue, Q.; Gao, Y.; Li, Q. Removal of trihalomethanes from reclaimed-water by original and modified nanoscale zero-valent iron: Characterization, kinetics and mechanism. Chem. Eng. J. 2015, 262, 1226-1236. [CrossRef]

27. Han, W.; Fu, F.; Cheng, Z.; Tang, B.; Wu, S. Studies on the optimum conditions using acid-washed zero-valent iron/aluminum mixtures in permeable reactive barriers for the removal of different heavy metal ions from wastewater. J. Hazard. Mater. 2016, 302, 437-446. [CrossRef] [PubMed]

28. $\mathrm{Mu}, \mathrm{Y}$; $\mathrm{Wu}, \mathrm{H}$.; Ai, Z. Negative impact of oxygen molecular activation on $\mathrm{Cr}(\mathrm{VI})$ removal with core-shell $\mathrm{Fe} @ \mathrm{Fe}_{2} \mathrm{O}_{3}$ nanowires. J. Hazard. Mater. 2015, 298, 1-10. [CrossRef] [PubMed]

29. Yoon, I.-H.; Yoo, G.; Hong, H.-J.; Kim, J.; Kim, M.G.; Choi, W.-K.; Yang, J.-W. Kinetic study for phenol degradation by ZVI-assisted Fenton reaction and related iron corrosion investigated by X-ray absorption spectroscopy. Chemosphere 2016, 145, 409-415. [CrossRef] [PubMed]

30. Rache, M.L.; García, A.R.; Zea, H.R.; Silva, A.M.T.; Madeira, L.M.; Ramírez, J.H. Azo-dye orange II degradation by the heterogeneous Fenton-like process using a zeolite Y-Fe catalyst-Kinetics with a model based on the Fermi's equation. Appl. Catal. B Environ. 2014, 146, 192-200. [CrossRef]

31. Xiang, W.; Zhang, B.; Zhou, T.; Wu, X.; Mao, J. An insight in magnetic field enhanced zero-valent iron $/ \mathrm{H}_{2} \mathrm{O}_{2}$ Fenton-like systems: Critical role and evolution of the pristine iron oxides layer. Sci. Rep. 2016, 6, 24094. [CrossRef] [PubMed]

32. Gonzalez-Olmos, R.; Holzer, F.; Kopinke, F.D.; Georgi, A. Indications of the reactive species in a heterogeneous Fenton-like reaction using Fe-containing zeolites. Appl. Catal. A Gen. 2011, 398, 44-53. [CrossRef]

33. Barhoumi, N.; Oturan, N.; Olvera-Vargas, H.; Brillas, E.; Gadri, A.; Ammar, S.; Oturan, M.A. Pyrite as a sustainable catalyst in electro-Fenton process for improving oxidation of sulfamethazine. Kinetics, mechanism and toxicity assessment. Water Res. 2016, 94, 52-61. [CrossRef] [PubMed]

34. Ji, F.; Li, C.; Zhang, J.; Deng, L. Heterogeneous photo-Fenton decolorization of methylene blue over $\mathrm{LiFe}\left(\mathrm{WO}_{4}\right)_{2}$ catalyst. J. Hazard. Mater. 2011, 186, 1979-1984. [CrossRef] [PubMed]

35. Yao, Y.; Chen, H.; Qin, J.; Wu, G.; Lian, C.; Zhang, J.; Wang, S. Iron encapsulated in boron and nitrogen codoped carbon nanotubes as synergistic catalysts for Fenton-like reaction. Water Res. 2016, 101, 281-291. [CrossRef] [PubMed]

36. Yao, Y.; Chen, H.; Lian, C.; Wei, F.; Zhang, D.; Wu, G.; Chen, B.; Wang, S. Fe, Co, Ni nanocrystals encapsulated in nitrogen-doped carbon nanotubes as Fenton-like catalysts for organic pollutant removal. J. Hazard. Mater. 2016, 314, 129-139. [CrossRef] [PubMed]

37. Guo, L.; Chen, F.; Fan, X.; Cai, W.; Zhang, J. S-doped $\alpha-\mathrm{Fe}_{2} \mathrm{O}_{3}$ as a highly active heterogeneous Fenton-like catalyst towards the degradation of acid orange 7 and phenol. Appl. Catal. B Environ. 2010, 96, 162-168. [CrossRef]

38. Du, D.; Shi, W.; Wang, L.; Zhang, J. Yolk-shell structured $\mathrm{Fe}_{3} \mathrm{O}_{4} @$ void@TiO 2 as a photo-Fenton-like catalyst for the extremely efficient elimination of tetracycline. Appl. Catal. B Environ. 2017, 200, 484-492. [CrossRef]

39. Seo, J.; Lee, H.-J.; Lee, H.; Kim, H.-E.; Lee, J.-Y.; Kim, H.S.; Lee, C. Enhanced production of reactive oxidants by Fenton-like reactions in the presence of carbon materials. Chem. Eng. J. 2015, 273, 502-508. [CrossRef] 
40. Kuan, C.-C.; Chang, S.-Y.; Schroeder, S.L.M. Fenton-like oxidation of 4-chlorophenol: homogeneous or heterogeneous? Ind. Eng. Chem. Res. 2015, 54, 8122-8129. [CrossRef]

41. Fayazi, M.; Taher, M.A.; Afzali, D.; Mostafavi, A. Enhanced Fenton-like degradation of methylene blue by magnetically activated carbon/hydrogen peroxide with hydroxylamine as Fenton enhancer. J. Mol. Liq. 2016, 216, 781-787. [CrossRef] 